\title{
AS FORMAS DE VIDA DO CONSUMO DIGITAL E DO CONSUMO TRADICIONAL
}

\author{
The Life Forms of Traditional and Digital Consumption
}

\author{
Las formas de vida del consumo digital y tradicional
}

\author{
Sérgio Bairon ${ }^{1}$ \\ Lawrence $\mathrm{Koo}^{2}$
}

\begin{abstract}
Resumo
Depois do aparecimento da Internet, passamos a ter uma distinção entre a nova vida de consumo que chamamos de consumo digital em contraposição à vida de consumo antes do seu aparecimento, presencial. Procuraremos analisar sob uma ótica não somente como hábitos de compra, mas como uma mudança na abordagem e no estilo de vida das pessoas. Entendemos que esse assunto é instigante e coloca diversas questões para discutição e reflexão, as quais pretendemos endereçar nas reflexões apresentadas.
\end{abstract}

Palavras-chave: consumo digital, consumo tradicional, consumidor curador e interatividade.

\begin{abstract}
After the emergence of the Internet, we now have a distinction between the new life we call consumer consumption as opposed to the digital consumer life before his appearance. We will seek to examine under a perspective not only as buying habits, but as a change in the approach and lifestyle. We understand that this issue is exciting and poses several questions for reflection and discussion.
\end{abstract}

Keywords: digital consumption, consumption traditional, healer and consumer interactivity.

1 Livre Docente em Comunicação pela Universidade de São Paulo. Pós-doutor pela Universidade Livre de Berlim, Alemanha. Doutor em Ciências pela FFCLH da USP. Professor do PPGCom ECA USP e do curso de Publicidade. Líder do CEDIPP - Centro de Comunicação Digital e Produção Partilhada do Conhecimento. sbairon@ gmail.com, bairon@usp.br

2 Pós Doutorando na ECA USP, junto ao CRP. Doutor e Mestre em Comunicação e Semiótica pela PUC SP. Professor da PUC SP no Departamento de Administração. Assessor da Fundasp, PUC SP. Membro pesquisador do GESC3 - Grupo de Estudos Semióticos em Comunicação, Cultura e Consumo. Lawrence@ pucsp.br 
As formas de vida do consumo digital e do consumo tradicional

de Sérgio Bairon e Lawrence Koo

\section{Resumen}

Después de la aparición de Internet, ahora tenemos una distinción entre la nueva vida de consumo que denominamos consumo digital frente a la vida antes de su aparición, o sea, concreta. Vamos a tratar de analizar desde una perspectiva no sólo como hábitos de compra, sino como un cambio en el enfoque y en lo estilo de vida. Entendemos que este tema es interesante y plantea varias preguntas para la reflexión y discusión, que tenemos la intención de abordar en las reflexiones presentadas.

Palabras-clave: consumo digital, el consumo tradicional, consumidor curador y interactividad.

\section{INTRODUÇÃO}

A priori, no aspecto teórico-filosófico, e no que diz respeito à noção de definição de essência de formar de vida, podemos afirmar que a única diferença entre o mundo da Internet e o mundo físico (comumente chamado de real), é que o primeiro é feito de bits e o segundo de átomos. A exceção desta diferença em relação a uma possível identidade essencial, a priori, não podemos identificar mais nada que diferencie o mundo da Internet e o mundo dos átomos. Com isto podemos afirmar que o que vamos analisar neste artigo, são todas formas de vida da linguagem que se estabelecem a posteriori da distinção entre bits e átomos. Neste sentido, ao falarmos de consumo tradicional estamos nos referindo ao universo cujo, a priori, habita os átomos e quando nos referirmos ao consumi digital nos referimos ao universo que, a priori, habita os bits.

Os tópicos temáticos que serão abordados estão relacionados às diferenças entre os objetos de átomos e os objetos de bits, a comunicação linear e a não-linear, a entropia e a taxionomia, a ausência ou presença de sistemas de busca, aos limites de estímulos, à presença ou à ausência de deslocamentos geográficos, ao comportamento de ações em grupo no mundo digital e no atômico, à presença ou à ausência da interatividade e do jogo, às noções de temporalidades na ação do consumo, aos ambientes das ações do consumo digital e atômicos, às diferenças entre o consumidor receptor e o consumidor curador e, por fim, às relações entre marca e consumidor no mundo dos átomos e no mundo dos bits.

\section{REFLEXÕES SOBRE A INTERNET CONTEMPORÂNEA - WEB 3.0}


Foram percorridas várias etapas no processo de desenvolvimento da Web, embora a sua trajetória aparentemente tenha sido contínua, mas podemos verificar que há pontos de inflexão bastante claros que divide os caminhos percorridos em estágios distintos. Sucintamente, podemos enumerar o primeiro estágio Web 1.0 que é caracterizado pela popularização de emails, sites organizacionais, portais e alguns buscadores de informações (Altavista etc.). O segundo estágio, Web 2.0, teve como precursor os Wiki’s, mecanismos de busca mais robustos, os blogs pessoais e esse estágio fica claramente caracterizada pelo aparecimento de plataformas de Redes Sociais. A evolução silenciosa da rede ficou para os desenvolvedores que implementaram, sem alarde, agentes inteligentes nas plataformas das redes sociais e nos mecanismos de busca que entram em ação quando os usuários da Web solicita uma informação ou um serviço e, sem que cada um de nós pudéssemos notar, por trás dos monitores (mais recentemente, as touchscreens dos smartphones). O papel principal da tecnologia que está sendo introduzida é a conexão dinâmica dos dados, das informações por meio dos "robots" para fornecer serviços e as facilidades que outrora eram somente fornecidas pelos humanos e de forma presencial. A Web 3.0 é a Web Semântica, que nos entende melhor, ela é mais "humana", mais articulada e mais prestativa. A riqueza das informações e como consequência, o potencial de prestação de serviços gerado pela nova etapa do desenvolvimento do mundo digital alterou profundamente as perspectivas do mundo de consumo. (Vide Figura 1).

Sob essa ótica, a evolução não ocorre somente nos hábitos de consumo, podemos observar que houve mudança em várias áreas da nossa vida cotidiana. A passagem do mundo tradicional para o mundo digital foi do átomo para bit, mas a mudança nas nossas vidas, quando houve a introdução do bit como elemento chave das nossas vidas, elas se tornaram mais abstratas, a Web 3.0 colabora em alto grau para esse abstracionismo do viver. Percebemos que o nosso consumo também evoluiu majoritariamente do físico para o experiencial. 
Figura 1. Evolução das gerações Web segundo (Spivack, 2007)

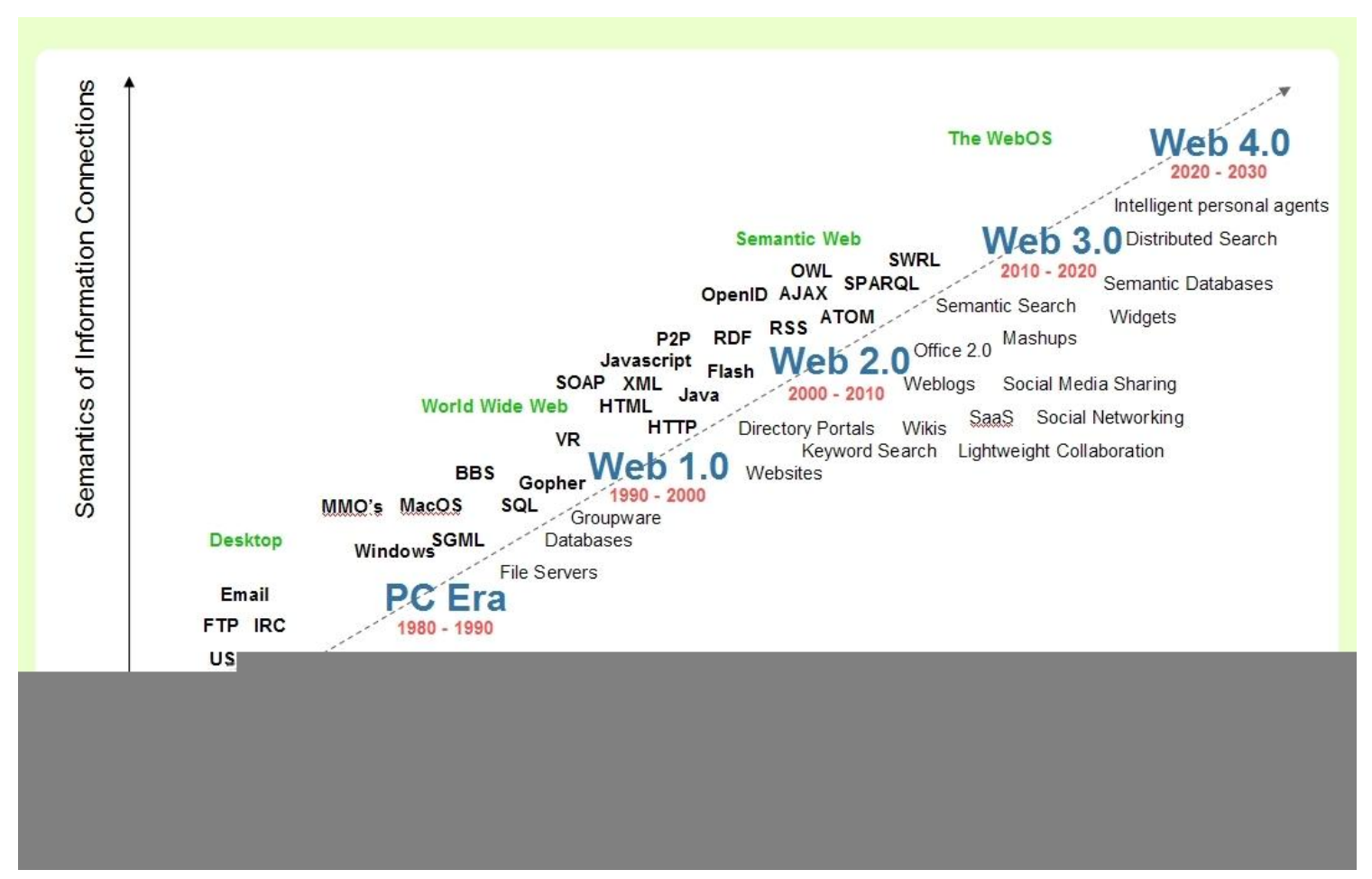

Juntamente com a Web 3.0 surgiu a tecnologia de Mobile Computing por meio da introdução dos smartphones e tablets, somando o ecosistema da cloud computing que dispensa a necessidade de se ter armazenamento de dados nos artefatos móveis, permite, portanto, a computação ubíqua dos usuários comuns com um custo aceitável para maioria da população, gerando uma nova forma de viver conectada ao mundo digital.

Descrevemos aqui que o consumo no mundo digital se diferencia não apenas da mudança do átomo para bit, como também nos conceitos do lócus e do tempo. A ubiquidade do mundo digital fornece a nós a possibilidade de uma transformação do estilo de vida, extensível à vida do consumo. Entendemos que esse processo já está consolidado, embora não esteja implantado, pois esse estilo de vida será exercido pela geração que já incorporou a computação ubíqua com parte integrante das suas vidas.

3. O POTENCIAL DO DESENVOLVIMENTO DA WEB PARA ALÉM DA WEB 3.0 
No nosso entender, a Web 3.0 já é um fato consumado, embora a sua terminologia ainda não está sendo empregada no nosso cotidiano, o nosso olhar se volta para as perspectivas futuras do encaminhamento do seu desenvolvimento. Consideremos provisoriamente de Web 4.0 o próximo estágio da Web, sendo assim, prospectemos sobre as possibilidades que o mundo digital poderá nos fornecer.

A incorporação permanente das tecnologias descritas nos parágrafos anteriores pelos usuários da rede gera um resultado natural da expectativa que já apoderamos dos recursos que estão no mundo digital, não nos preocupamos em acumular muitas das coisas que temos de armazenar nos nossos arquivos e artefatos particulares. Entendemos que fazemos parte dos nós da rede e, que mesmo com algumas restrições, há o consenso que temos a rede à nossa disposição. Queremos deixar claro que cada nó da rede pode ser uma pessoa, um ser humano, ou um artefato de software que antigamente chamaríamos de robô, ou ainda uma plataforma etc. Queremos pontuar aqui que a nossa capacidade, a nossa inteligência é estendida por meio da nossa conexão permanente à rede. Esse fato é transformador no nosso viver não apenas nos nossos hábitos como também no nosso ser. Somos mais inteligentes com o desenvolvimento da Web, em outras palavras, a nossa inteligência é aumentada.

Essa tese é corroborada pela percepção do Novak Spivack (2007) como pode ser vista na figura 2. A consequência desse encaminhamento nos indicia que a nossa vida cognitiva mudou e continuará a mudar, inclusive a nossa vida cognitiva e consumo.

\section{NOVAS FORMAS DE VIDA COGNITIVAS DE CONSUMO}

No consumo tradicional (atômico) temos a presença física dos objetos de consumo que se apresentam a nós. Nestes momentos nossas capacidades de imaginar os objetos está solapada, pois o contato imediato cria uma fissura com o imaginário. No caso do objeto na forma digital, estamos abertos para a imaginação, pois dispostos à colocar nas manifestações visuais, verbais e sonoras, toda nossa forma de projeção imaginária. Ou seja, por um lado, podemos afirmar que manusear o objeto digital possibilita reforçar as fantasias no ato do consumo. Por outro lado, o objeto atômico oferece um "choque real". As diferenças básicas estão calcadas nas 
Figura 2. Metaweb - conexão de inteligências (Spivak, 2007)

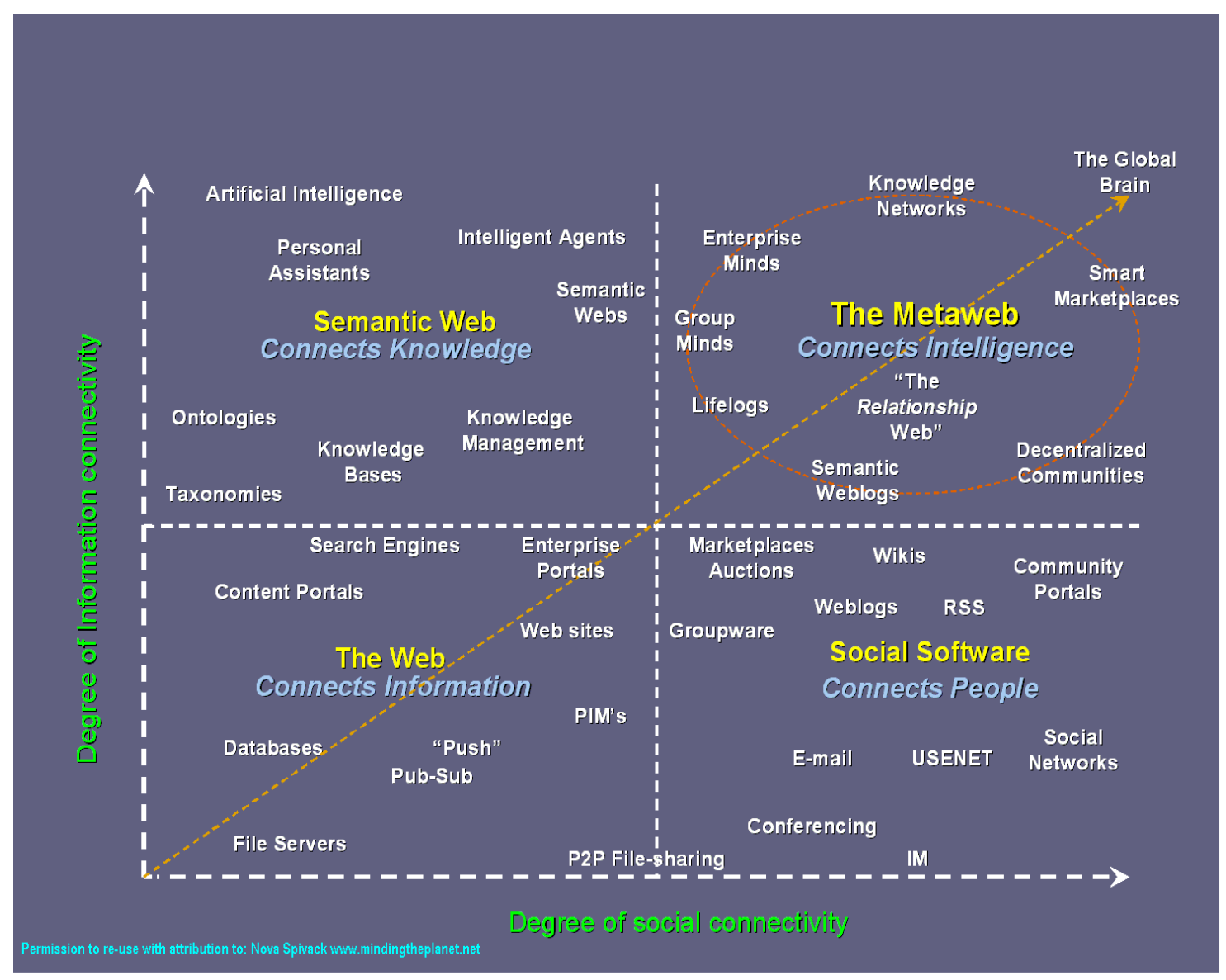

possibilidades de explorar formas diversas de conhecer um produto no mundo digital e, em contrapartida, estas possibilidades não existem mais no interior das ações físicas das relações de consumo.

Outra questão que reinaugura a ação do consumo no mundo digital está no fato de que enquanto o consumo tradicional depende, primordialmente, de um processo de comunicação linear (comerciais de TV, propagandas impressas etc.), o consumo digital carrega uma grande potencialidade não linear, já que podemos explorar as mais diversas opções de oferta de conteúdo sobre o produto e/ou serviço, por meio da exploração interativa dos produtos ou serviços. No entanto, apesar da interatividade é preciso tomar cuidado com o fenômeno da entropia, ou seja, as informações apresentadas em excesso, o que geralmente acontece quando simplesmente transferimos a lógica tradicional para o meio digital. Já no âmbito do consumo digital, podemos organizar as informações de maneira consequente e taxionomicamente 
As formas de vida do consumo digital e do consumo tradicional

de Sérgio Bairon e Lawrence Koo

competentes, pois nas ações do consumo digital dependemos, fundamentalmente, de uma organização e classificação do conteúdo.

Uma das grandes vantagens dos processos de comunicação que ocorrem no interior de ambientes digitais de consumo são os sistemas de busca. Assim como ocorre por meio da presença física, os recursos de estímulos para pontos de venda digitais, também dependem de um cuidadoso investimento, ou seja, os "pontos de venda" podem e devem contar com o maior número possível de recursos: $3 \mathrm{D}$, câmera $360^{\circ}$, efeitos em flash, realidade aumentada etc.. Podemos imaginar uma regra para isto, afirmando que quanto maior o valor agregado ao produto, maior é a quantidade de recursos interativos que devemos utilizar. Um produto com alto valor agregado, por exemplo, um automóvel, uma roupa especial etc., podem ser oferecidos por meio de efeitos tridimensionais e realidade aumentada com recursos sonoros ou informações verbais construídas taxionomicamente. O contrário, também é válido, quanto menor o valor agregado ao produto ou serviço, menor o número de recursos cognitivos. Não podemos deixar de afirmar que as possibilidades de exploração destas tecnologias estão cada vez maiores e mais baratas, sendo que os grandes desafios estão localizados nas estratégias de exposição cognitiva dos objetos e, não mais, nos investimentos em know how puramente técnicos para seu desenvolvimento.

\section{5. À CAMINHO DO CONSUMIDOR CURADOR}

O fato de o consumidor pesquisar, buscar, mexer nos objetos, experimentar etc., do lugar de onde estiver (em casa, no trabalho, no trânsito etc.), torna o processo de consumo poderosamente familiar. Isto ocorre, fundamentalmente, porque a possibilidade de ampliação e de expansão das atividades que nos cercam no dia a dia, acontece justamente pelos equipamentos mobile que se multiplicam na atualidade. O que levamos conosco para onde formos (ou estivermos) é nossa condição cotidiana de existência: amigos, conhecidos, família, nossa casa etc.. Este fenômeno contemporâneo redimensiona o conceito de habitação, deslocando-o e o tornando independente dos espaços constituídos por átomos. Estas novas condições de transposições espaciais acabam criando um consumidor mais exigente e mais ativo, porque traz para dentro de sua condição de familiaridade as empresas e produtos que elege como parceiros. Neste sentido, é que competentes ações cognitivas como poderosos sistemas de busca ou efeitos 
competentes agregados aos produtos ou serviços, são ações fundamentais como estratégias de conquistar uma maior intimidade com os consumidores.

Estas são algumas das razões que fazem com que no consumo digital os consumidores, cada vez mais, sejam curadores do produto ou da marca. Eles agem transmitindo, compilando, comentando, compartilhando e recomendando conteúdos, produtos, compras e experiências estéticas, tanto para os seus amigos quanto para o público em geral. O princípio do consumidor como interator (ator que interage) pressupõe, que ele age como um curador, ou seja, que ele detém uma grande capacidade comunicativa de divulgação e/ou retorno com referência ao consumo. O mundo que cria o consumidor digital é o mesmo que promove a radicalização do consumidor crítico. Em outras palavras, é o mesmo que afirmar que os níveis de feedback dos consumidores saiu totalmente do controle das empresas. Um dos exemplos mais clássicos encontramos nas compras coletivas, nas quais movimentos de compra em grupo (Flash vendas) são profundamente expressivos do comportamento deste consumidor contemporâneo: efêmero e impulsivo, por meio dos quais atua de forma contundente a relação entre preço e oportunidade, sempre no interior de ambientes familiares.

\section{A REESTRUTURAÇÃO DO ESPAÇO E DO TEMPO: MANIFESTAÇÕES CRONOTÓPICAS}

Ao contrário do consumo tradicional, o consumo digital é mais compatível tanto com a instantaneidade da decisão quanto com a busca pragmática e cuidadosa. O consumo no mobile não define espaço, pois a decisão e a ação do consumo acompanha a grande movimentação espacial da sociedade contemporânea. Em um projeto inédito no Brasil, a rede Magazine Luiza criou um novo canal de venda em que qualquer pessoa poderá criar sua vitrine no Facebook e no Orkut com produtos da loja virtual da rede e vender a seus amigos. Chamado de Magazine Você, a novidade é uma aposta no social commerce.

São justamente estas características de interatividade e conectividade que fazem dos consumidores verdadeiros sócios da Marca. Este é um novo conceito que quanto antes for compreendido, melhor! 
As formas de vida do consumo digital e do consumo tradicional

de Sérgio Bairon e Lawrence Koo

\section{CONSIDERAÇÕES FINAIS: OS DESAFIOS ESTÃO POSTOS}

Em que medida existem diferenças e proximidades entre o consumo "real-presencial" e o consumo digital? Como as características não-lineares da comunicação digital podem influenciar e incentivar o consumo digital? Qual a relação entre a compra coletiva e as características da conectividade no mundo digital? Existem categorias de produtos/serviços que são privilegiadas no consumo digital? Porquê? Quais as principais resistências em relação ao consumo digital? Quais as diferenças entre o consumidor receptor e o consumidor interator? Quais as principais vantagens do consumo digital? Por quais razões está crescendo vertiginosamente? Porque podemos afirmar que o consumo digital deve ser compreendido na semântica de uma espontaneidade planejada? Quais as características comportamental da nova classe média que aumentam a tendência de consumo digital? Qual a relação que existe entre serviços gratuitos na WEB e o consumo digital? Quais as relações entre a busca de informações na WEB e o aumento do consumo nas lojas físicas?

Todos esses desafios nos inspiram no sentido de continuar as pesquisas teóricas e empíricas acerca das relações de consumo presenciais e digitais e suas interfaces e interpenetrações.

\section{REFERÊNCIAS BIBLIOGRÁFICAS}

ADEY, Peter. Mobility (Key Ideas in Geography).London-New York, Routledge, 2010.

APPADURAI, Arjun. Dimensões culturais da globalização. Lisboa, Teorema, 2004.

BAIRON, Sérgio. Interdisciplinaridade educação, história da cultura e hipermídia.. São Paulo, Futura, 2002.

. Multimídia. São Paulo, Global, 1995.

. O que é Hipermídia. São Paulo, Brasiliense, 2011.

. "A comunicação nas esferas, a experiência estética e a hipermídia." Revista USP, v. 86 , p. $16-27,2010$.

BOLTER, Jay David. Remediation. Cambridge-Massachusetts, MIT Press, 2002.

BURKE, Peter. Hibridismo cultural. São Leopoldo, Ed. Unisinos, 2003.

CRARY, Jonathan. Suspensions perception. Cambridge e London, MIT Press, 2001. 
As formas de vida do consumo digital e do consumo tradicional de Sérgio Bairon e Lawrence Koo

JENKINS, henry. Convergence culture. New york - london, new york university press, 2006.

LANDOW, George. Hypertext 3.0: Critical Theory and New Media in an Era of Globalization.

Baltimore, John Hopkins University Press. 2006.

MOLZ, Jennie Germann. Travel Connections. London-New York, Routledge, 2012.

MOORES, Shaum. Media, Place and Mobility. London-New York, Routledge, 2012.

Connectivity, Networks and Flows: Conceptualizing Contemporary Communication (Communication, Globalization and Cultural Identity). London-New York, Routledge, 2008.

PEREZ, C. ; BAIRON, S. . Signos da mobilidade: a ressignificação da liberdade na campanha publicitária "go" Visa. Comunicação, Mídia e Consumo (São Paulo. Impresso), v. 7, p. 83-103, 2010.

PINK, Sarah. The future of visual anthropology. New York, London, Routledge, 2006

Roy, R. Ranian. Handbook of Mobile Ad Hoc Networks for Mobility Models. New York, Springer, 2011.

SPIVACK, N., Making Sense of the Semantic Web and, Twine <http://novaspivack.typepad.com/nova_spivacks_weblog/2007/11/making-senseof.html>. 2007. Acessado em 29 nov 2010

URRY, John. Mobilities. Cambridge, Polity Press, 2007.

ZIZEK, Slavoj. A visão em paralaxe. São Paulo, Ed. Boi Tempo. 2008.

Artigo submetido: 03/2012

Artigo aprovado: 06/2012 